\title{
USO DA PODA SECA E DA PODA VERDE PARA OBTENÇÃO DE DUAS SAFRAS POR CICLO VEGETATIVO EM TRÊS CULTIVARES DE VIDEIRA ${ }^{1}$
}

\author{
RAFAEL ANZANELLO², PAULO VITOR DUTRA DE SOUZA ${ }^{3}$, PEDRO FERREIRA COELHO ${ }^{4}$
}

RESUMO - Foram avaliadas épocas de poda seca e de poda verde visando ao alcance de duas safras por ciclo vegetativo nas videiras 'Niagara Branca', 'Niagara Rosada' e 'Concord', cultivadas em sistema de espaldeira. O experimento foi realizado na Estação Experimental da UFRGS, em Eldorado do Sul - RS, na safra de 2007/2008. As plantas foram submetidas aos seguintes tratamentos: T1 (poda seca em 20-07-07 e poda verde em 15-11-07); T2 (poda seca em 20-07-07 e poda verde em 17-12-07); T3 (poda seca em 2208-07 e poda verde em 15-11-07), e T4 (poda seca em 22-08-07 e poda verde em 17-12-07), sendo a poda de inverno feita em cordão esporonado, e a poda verde, mediante desponte do sarmento a partir da quarta gema acima do último cacho. Avaliaram-se a produção por planta, a massa dos cachos, os sólidos solúveis totais (SST), a acidez total titulável (ATT), a relação SST/ATT, o potencial da água na folha e a relação folha:fruto, de ambas as safras. Os resultados demonstraram que a execução de uma poda seca associada a uma poda verde permitiu obter duas safras de uva por ciclo vegetativo em ‘Niagara Branca', Niagara Rosada e 'Concord', sendo mais eficiente quando a poda seca foi realizada em agosto, associada à poda verde em novembro. A ‘Niagara Branca’ apresentou maior potencial para produzir uma segunda colheita, comparativamente à 'Niagara Rosada’ e ‘Concord'. Os frutos oriundos da poda verde apresentaram menor valor de SST, maior ATT e menor relação SST/ATT em relação aos obtidos na safra normal.

Termos de indexação: manejo da poda, práticas culturais, fisiologia vegetal, Vitis labrusca.

\section{USE OF WINTER PRUNING AND GREEN PRUNING FOR OBTAINING TWO HARVESTS BY VEGETATIVE CICLE OF THREE VINE CULTIVARS}

\begin{abstract}
This study aimed to evaluate the effects of winter and green pruning for obtaining two harvests per vegetative cycle for Niagara Branca, Niagara Rosada and Concord grapevine cultivars conducted by cordon training. The experiment was performed at the Agronomic Experimental Station of Eldorado do Sul, Rio Grande do Sul State, Brazil, during the 2007/2008 harvest. Grapevines were submitted to the following treatments: T1 (winter pruning on 07/20/07 and green pruning on 11/15/07), T2 (winter pruning on 07/20/07 and green pruning on 12/17/07), T3 (winter pruning on 08/22/07 and green pruning on 11/15/07) and T4 (winter pruning on 08/22/07 and green pruning on 12/17/07). The winter pruning was performed by means of a short pruning, while the green pruning was performed by pruning the shoot, starting from the fourth bud above the last grape cluster. The grapevine production, cluster weight, total soluble solids (SST), total titratable acidity (ATT), SST/ATT ratio, water potential in the leaf and leaf/fruit ratio were evaluated for the two crops. Results demonstrated that a winter pruning associated to a green pruning permitted to obtain two harvests of 'Niagara Branca', 'Niagara Rosada' and 'Concord' cultivars per vegetative cycle. The treatment T3 was the most efficient to obtain a second harvest in the same vegetative cycle. The Niagara Branca showed high potential for a second harvest when compared to the Niagara Rosada and Concord grapevines cultivars. Grapes under the green pruning had lower SST, larger ATT and smaller SST/ATT ratio compared to grapes from regular harvest.
\end{abstract}

Index terms: pruning management, cultural practices, plant physiology, Vitis labrusca.

\footnotetext{
${ }^{1}$ (Trabalho 049-09). Recebido em: 18-02-2009. Aceito para publicação em: 19-10-2009.

${ }^{2}$ Eng. Agr. MSc., Doutorando do PPGFitotecnia, Dep. Hortic. e Silvic. Fac. Agron. UFRGS, Av. Bento Gonçalves, 7712 Caixa Postal 15100 CEP 91501-970, Porto Alegre-RS. Bolsista CNPq. E-mail: ranzanello@yahoo.com.br Autor para correspondência.

${ }^{3}$ Eng. Agr., Dr. Prof. Associado, Fac. Agron. UFRGS, Av. Bento Gonçalves, 7712 CEP 91501-970, Porto Alegre-RS. Bolsista CNPq. E-mail: pvdsouza@ufrgs.br

${ }^{4}$ Graduando, Dep. Hortic. e Silvic., Fac. Agron. UFRGS, Av. Bento Gonçalves, 7712 CEP 91501-970, Porto Alegre-RS. Bolsista CNPq, E-mail: pedrofcoelho@gmail.com
} 


\section{INTRODUÇÃO}

A cultura da videira tem uma marcada importância socioeconômica e cultural para diversos países. Esta atividade estende-se por mais de 7 milhões de hectares (ha) em cultivo, com uma produção de aproximadamente 66 milhões de toneladas e produtividade média de $9.200 \mathrm{~kg} \mathrm{ha}^{-1}$, segundo dados da FAO (2008).

No Brasil, a produção de uvas localiza-se principalmente nas regiões Sul, Sudeste e Nordeste (Camargo, 1994). No Rio Grande do Sul, o cultivo da videira encontra-se predominantemente na Serra do Nordeste, além do Planalto das Araucárias, do Planalto da Campanha, da Depressão Central e do Planalto Uruguaio-Sul-Rio-Grandense (Tonietto \& Falcade, 2003). No ano de 2007, o total de vinhedos no Estado foi de 40,3 mil ha (IBGE, 2007), sendo cultivadas basicamente cultivares americanas e híbridas, com a produção obtida em uma única safra, concentrada entre os meses de janeiro e fevereiro.

Chadha \& Shikhamany (1999) relatam que a diferenciação das gemas na cultura da videira coincide com a fase de frutificação ou pegamento de frutos. Dessa forma, com a adoção de uma poda seca no inverno, associada a uma poda verde no verão, é possível produzir duas safras de uva por ciclo vegetativo da planta. Tal condição permitiria modificar o cenário vitícola da região Sul do Brasil, oferecendo vantagens econômicas ao viticultor e de disponibilidade da fruta ao consumidor.

Segundo Fochesato et al. (2007), o sucesso produtivo da segunda safra está atrelado à combinação entre épocas específicas de poda de inverno e de poda verde. Souza \& Fochesato (2007) afirmam que a poda verde, se realizada precocemente, leva a uma pequena produção, devido à insuficiente diferenciação de gemas. E, se executada tardiamente, pode não atingir o ponto de maturação ideal em virtude de a mesma ocorrer no outono, época de baixas temperaturas e insolação.

No Rio Grande do Sul, condições climáticas propícias para o alcance de duas produções de uva por ano encontram-se junto à região da Depressão Central, conforme estudos apresentados por Souza \& Fochesato (2007) e Fochesato et al. (2007).

Nesse contexto, este trabalho teve por objetivo avaliar o comportamento produtivo das cultivares Niagara Branca, Niagara Rosada e Concord, submetidas a diferentes épocas de poda seca e de poda verde, visando à obtenção de duas safras de uva por ciclo vegetativo da videira, na região ecoclimática da Depressão Central do Rio Grande do Sul

\section{MATERIAL E MÉTODOS}

O experimento foi conduzido na Estação Experimental Agronômica da UFRGS (3005’27’'S; 5140’18’W; altitude de $46 \mathrm{~m}$ ), localizada no município de Eldorado do Sul - RS, na região da Depressão Central do Estado do Rio Grande do Sul. O solo do local é classificado como Argissolo Vermelho distrófico de textura argilosa e relevo ondulado, tendo como substrato o granito (Mello et al., 1966). Normalmente, são solos bem drenados, fortemente ácidos, com saturação e soma de bases baixa e com teores baixos de matéria orgânica. Segundo Köeppen, o clima da região é classificado como Cfa. A precipitação pluviométrica anual média é de 1.445,8 mm, e a umidade relativa do ar anual média é 77\%. A radiação solar global média é de $12,39 \mathrm{MJ} \mathrm{m}^{-2} \mathrm{dia}^{-1}$. O número médio de horas de frio com temperaturas inferiores a $7,2^{\circ} \mathrm{C}$ é de 213 horas de maio a agosto (Bergamaschi et al., 2003).

Para o experimento, utilizaram-se três cultivares de videira, a Niagara Branca, a Niagara Rosada e a Concord, todas Vitis labrusca L., enxertadas sobre o porta-enxerto 101-14 mgt, com 16 anos de idade. As plantas encontravam-se espaçadas por 1,20 $\mathrm{m}$ dentro da fila e $3 \mathrm{~m}$ entre filas, sustentadas pelo sistema de condução tipo espaldeira, com 3 fios de arame, espaçados $55 \mathrm{~cm}$ cada.

O delineamento experimental utilizado foi o inteiramente casualizado, com seis repetições e uma planta por parcela, sendo testadas duas épocas de poda de inverno (20-07-2007, 22-08-2007) e duas épocas de poda verde (15-11-2007, 17-12-2007). Os tratamentos consistiram em: T1 - poda seca em 20-07-2007 e poda verde em 15-11-2007; T2 - poda seca em 20-07-2007 e poda verde em 17-12-2007; T3 - poda seca em 22-08-2007 e poda verde em 1511-2007, e T4 - poda seca em 22-08-2007 e poda verde em 17-12-2007.

A poda seca consistiu em deixar-se duas a três gemas por ramo, em cordão esporonado. Todas as plantas foram submetidas à superação de dormência mediante aplicação de cianamida hidrogenada a $2 \%$, imediatamente após a poda seca. Já a poda verde foi feita mediante o desponte do sarmento a partir da quarta gema acima do último cacho, e a eliminação das feminelas ou netos, forçando a brotação das gemas produtivas.

Avaliaram-se, no decorrer do experimento, a produção por planta (kg); a massa média dos cachos (g); os sólidos solúveis totais (SST); a acidez total titulável (ATT), e a relação SST/ATT, em ambas as safras. De forma complementar, foram medidos o potencial da água na folha ao longo do ciclo e a 
relação folha:fruto para a segunda produção.

A produção por planta foi obtida pela pesagem dos cachos colhidos em balança eletrônica, marca Urano, modelo UDC 30000/5. A massa média dos cachos foi obtida pela divisão entre a produção por planta e o número de cachos por planta.

Para a análise da composição química dos frutos da primeira e segunda safras foram coletados dez e cinco cachos de uva por unidade experimental, respectivamente. O valor de SST foi determinado em refratômetro de mesa, modelo 2WAJ, a partir de amostra de 20 microlitros de mosto extraído por prensagem manual. Para a determinação da ATT, $6 \mathrm{~g}$ de polpa foram macerados em almofariz, e posteriormente diluídos em $100 \mathrm{~mL}$ de água destilada. Procedeu-se à titulação da amostra sob agitação, com solução de $\mathrm{NaOH} 0,1 \mathrm{~N}$ previamente padronizada com biftalato de potássio. Os resultados foram expressos em $\mathrm{cmol} \mathrm{L}^{-1}$, determinados pela quantidade de solução gasta até atingir pH 8,1.

A relação SST/ATT foi obtida pela razão entre SST e ATT em \% de equivalente de ácido tartárico. A \% de equivalente de ácido tartárico (AT) foi calculada pela seguinte equação:

$\%$ AT $=(\mathrm{mL} \mathrm{NaOH}$ gasto $\times \mathrm{N}(\mathrm{NaOH}) \times$ 0,075 (fator de correção ác. tartárico) x 100)/6 g (peso amostra).

O potencial da água na folha foi medido através de câmara de pressão (Schollander et al., 1965). Utilizaram-se dez folhas coletadas aleatoriamente na área de cultivo, em folhas totalmente expandidas encontradas próximas aos cachos. Os dias avaliados foram: 15-09-07; 13-10-07; 22-11-07; 20-12-07; 16-01-08; 18-02-08; 21-03-08; 17-04-08 com determinações antes do nascer do sol (potencial de base) e após o meio dia solar (potencial mínimo). Já a relação folha:fruto foi obtida segundo metodologia proposta por Alleweldt \& Fader, citados por Gil (2000), método baseado na quantificação da área foliar em $\mathrm{m}^{2}$, e na massa de cachos produzida por planta em kg.

O índice de área foliar (IAF) foi calculado pela seguinte fórmula:

$$
I A F=\frac{N F / P l}{S / P l} \times A F
$$

sendo: NF/Pl o número de folhas por planta; $S / P l$ a área de solo ocupado por planta, e $A F$ a área média calculada das folhas. A área de cada folha (AF) foi calculada pelo produto entre comprimento versus largura das folhas. Para a calibração das estimativas pelo produto comprimento $x$ largura foliar, foram coletadas amostras de 150 folhas por cultivar, escolhidas aleatoriamente ao longo do dossel vegetativo das plantas, e determinada sua área em medidor de área foliar Li-cor, modelo LI 3000.

A relação folha:fruto foi contabilizada da virada de cor das bagas à sua colheita nas cvs. Niagara Rosada e Concord, e do início da maciez das bagas à sua colheita na cv. Niagara Branca, ao longo da maturação da segunda produção. Para a mensuração, foi considerada a área foliar dos ramos provenientes da poda seca assim como das brotações procedentes da poda verde.

As variáveis de produção quantitativa e produção qualitativa foram submetidas à análise de variância. Os resultados com diferenças significativas, pelo teste "F”, tiveram suas médias submetidas ao teste de Duncan, ao nível de significância de 5 \% de probabilidade.

\section{RESULTADOS E DISCUSSÃO}

Nas Tabelas 1 e 2, são apresentadas as avaliações da produção quantitativa e qualitativa da primeira safra de uva obtida ao longo dos meses de dezembro e janeiro, para as cultivares Niagara Branca, Niagara Rosada e Concord. A massa média dos cachos e a produção média por planta não variaram entre a 'Niagara Branca’ e 'Niagara Rosada', porém diferiram significativamente para a cultivar Concord, que apresentou menor produtividade por planta e menor massa por cacho. Já, quanto à análise qualitativa, verificou-se maior teor de acidez e menor teor de sólidos solúveis totais para frutos da cultivar Concord, comparativamente aos frutos da 'Niagara Branca' e da 'Niagara Rosada'. Tais características devem-se, provavelmente, às diferenças genéticas inerentes às cultivares em estudo (Giovaninni, 1999).

Em relação aos tratamentos de poda, verificaram-se diferenças significativas entre os mesmos para a massa média dos cachos e os sólidos solúveis totais dos frutos (Tabelas 1 e 2). O tratamento T3 exibiu cachos de menor massa e menor teor de açúcares nas cultivares Niagara Branca e Niagara Rosada, e mostrou leve tendência ao decréscimo na cultivar Concord. Isso provavelmente se deva à maior alteração na rota de fotoassimilados ocorrida no tratamento T3, em função do maior número de brotações procedentes da poda verde (Tabela 3), as quais atuavam como drenos aos fotoassimilados destinados ao desenvolvimento e à maturação da primeira produção.

Para a segunda safra, colhida entre os meses de março e abril, o tratamento T3 proporcionou maior produção por planta e cachos de maior massa absoluta, sendo a cultivar Niagara Branca mais pro- 
pensa à adoção do manejo estabelecido (Tabela 4). Tal técnica permitiria ampliar o período de oferta da fruta ao consumidor e obter uvas tardias com maior preço de mercado, no período de entressafra para o Estado do Rio Grande do Sul. Resultados parecidos foram obtidos por Anzanello et al. (2008), que utilizando poda de inverno em agosto e uma época de poda verde em novembro, alcançaram produção de 1,49 kg planta-1 para a 'Niagara Branca' e 0,79 kg planta $^{-1}$ para a 'Concord'. Fochesato et al. (2007) também conseguiram, nas mesmas épocas de podas, 3,64 kg planta-1 para a 'Niagara Branca' e 1,37 kg planta $^{-1}$ para a 'Niagara Rosada'.

A maior produção do tratamento T3 está diretamente relacionada ao maior número de brotações mistas emergidas dos ramos submetidos à poda verde $(r=0,89)$. A razão pela qual o tratamento T3 proporcionou maior número de brotações (Tabela 3) está provavelmente ligada à atividade metabólica da planta, quando da realização da poda verde. Como o tratamento T3 teve a combinação específica de poda seca e de poda verde espaçada em 3 meses, os ramos, quando podados em novembro, encontravam-se tenros, dotados de circulação de seiva rápida e intensa, favorecendo a brotação das gemas. Já nos tratamentos T1 e T4, cujas épocas de poda ficaram espaçadas em quatro meses, assim como o tratamento $\mathrm{T} 2$, em cinco meses, os ramos encontravam-se bastante lignificados no momento da realização da poda verde, com as gemas provavelmente já em estado de dormência, dificultando ou impedindo que as mesmas brotassem.

A maior brotação do tratamento T3 pode também ter sido influenciada por processo controlado por hormônios. Junto à brotação, há a necessidade de alta relação citocinina/giberelina endógena (Shaltout et al., 1988). Dessa forma, como a poda verde no tratamento T3 foi realizada quando os frutos da primeira safra se encontravam na fase de "ervilha", e nos demais tratamentos, a mesma foi executada numa fase mais avançada de desenvolvimento do cacho, a maior síntese de giberelinas causada pela presença de sementes maiores e mais maduras nos tratamentos T1, T2 e T4 pode ter-se tornado um fator impeditivo à brotação das gemas, por ter diminuído a relação citocinina/giberelina presente na planta.

De modo geral, o baixo rendimento das plantas submetidas à poda verde pode estar atrelado ao período de déficit hídrico ocorrido no verão (Figuras 1A e 2), o qual afetou, além da emissão, o desenvolvimento dos brotos responsáveis pela segunda safra. À semelhança desse experimento, Schiedeck (1996) também verificou baixa brotação das gemas em 'Niagara Rosada' como causa da de- ficiência hídrica do solo, o que poderia ser contornado pelo manejo da irrigação. Souza \& Fochesato (2007), trabalhando com as cvs. Niagara Branca e Niagara Rosada, também verificaram baixo rendimento, quando submetidas à poda verde em 10 de novembro, devido ao período de estiagem ocorrido após a poda.

Em relação à qualidade dos frutos da segunda safra, houve diferenças significativas dos SSTs entre os tratamentos (Tabela 5), tendo o T3 apresentado menor teor de açúcares para as cultivares Niagara Branca e Niagara Rosada. Para a cv. Concord, uma tendência ao decréscimo do SST também foi observada para o tratamento T3. Tal comportamento pode ser justificado pela menor área foliar encontrada por fruto no tratamento T3 quando da maturação da segunda produção (Tabela 6). Quanto à ATT, nos frutos colhidos na segunda safra, somente houve diferenças significativas entre cultivares, com valor inferior à 'Concord' (Tabela 5).

Em relação à análise comparativa das duas produções colhidas, a qualidade da segunda safra mostrou-se inferior à primeira, apresentando menor valor de SST, maior acidez e menor relação SST/ATT para 'Niagara Branca', 'Niagara Rosada’e 'Concord' (Tabela 7).

O menor índice de SST dos frutos da segunda safra pode explicar-se pelo excesso de chuvas presenciado durante os meses de março e abril, período em que ocorreu o amadurecimento da segunda produção (Figura 1A). Segundo Tonietto \& Falcade (2003), altos níveis de precipitação no período de maturação prejudicam a qualidade da uva por impossibilitar concentração satisfatória de açúcares nos frutos, promover podridões e necessitar de colheitas antecipadas. De acordo com Ojeda et al. (2004), para o incremento da qualidade das uvas, o potencial de base da água na folha deve situar-se entre -0,20 a -0,60 MPa, faixa evidenciada na maturação das uvas da primeira safra, ocorrida entre dezembro e janeiro, porém aquém do desejável para os frutos da segunda safra (Figura 2).

O aumento médio no valor de ATT da segunda colheita, comparado à primeira, possivelmente tenha ocorrido devido à menor degradação dos ácidos orgânicos (Pommer et al., 2003). Segundo Guerra (1992), os ácidos são os compostos preponderantemente consumidos à noite para a manutenção do metabolismo da planta. Assim, a maior queda da temperatura à noite, junto à maturação da segunda produção (Figura 1A), atribuiu às plantas menor dispêndio de energia e, consequentemente, maior acúmulo de ácidos nos seus cachos. Champagnol (1984) afirma que a degradação dos ácidos verificados no mosto da uva também é dificultada com a redução da luminosidade, característica evidenciada ao longo da maturação dos frutos 
da segunda safra (Figura 1B).

A relação SST/ATT foi maior para a 'Niagara

Branca' e para a 'Niagara Rosada', devido ao seu menor teor de acidez e maior teor de sólidos solúveis totais comparativamente à 'Concord', em ambas as safras (Tabelas 2 e 5). A relação SST/ATT mostrou-se insatisfatória para a cultivar Concord, ficando aquém do desejável para o seu consumo in natura, principalmente nos frutos da segunda colheita. Camargo (1994) atribui uma faixa aceitável na relação SST/ ATT para o consumo de uvas de mesa, no mínimo, entre 15 e 16.

TABELA 1 - Produção média por planta e massa média do cacho na primeira colheita das cvs.Niagara Branca (NB), Niagara Rosada (NR) e Concord. Eldorado do Sul-RS, 2007/2008.

\begin{tabular}{ccccccccc}
\hline \multirow{2}{*}{ Cultivar } & \multicolumn{3}{c}{ Produção média $\left(\mathrm{kg} \mathrm{planta}^{-1}\right)$} & \multicolumn{5}{c}{ Massa média $\left(\mathrm{g} \mathrm{cacho}^{-1}\right)$} \\
\cline { 2 - 8 } & T1 & T2 & T3 & T4 & T1 & T2 & T3 & T4 \\
\hline NB & $11,06 \mathrm{aA}$ & $11,78 \mathrm{aA}$ & $10,15 \mathrm{aA}$ & $11,03 \mathrm{aA}$ & $172,08 \mathrm{abA}$ & $185,83 \mathrm{aA}$ & $157,75 \mathrm{bA}$ & $171,42 \mathrm{abA}$ \\
NR & $10,58 \mathrm{aA}$ & $10,95 \mathrm{aA}$ & $10,17 \mathrm{aA}$ & $10,72 \mathrm{aA}$ & $172,00 \mathrm{abA}$ & $177,38 \mathrm{aA}$ & $152,67 \mathrm{bA}$ & $166,25 \mathrm{abA}$ \\
Concord & $8,17 \mathrm{aB}$ & $8,34 \mathrm{aB}$ & $7,71 \mathrm{aB}$ & $7,94 \mathrm{aB}$ & $88,17 \mathrm{aB}$ & $99,83 \mathrm{aB}$ & $84,50 \mathrm{aB}$ & $85,67 \mathrm{aB}$ \\
\hline CV (\%) & \multicolumn{6}{c}{23,98} & \multicolumn{5}{c}{15,41} \\
\hline
\end{tabular}

Médias seguidas pela mesma letra, minúscula na linha e maiúscula na coluna, não diferem significativamente, pelo teste de Duncan, a $5 \%$ de probabilidade.

TABELA 2 - Sólidos solúveis totais (SST) e acidez total titulável (ATT) dos frutos na primeira colheita das cvs. Niagara Branca (NB), Niagara Rosada (NR) e Concord. Eldorado do Sul-RS, 2007/2008.

\begin{tabular}{ccccccccc}
\hline \multirow{2}{*}{ Cultivar } & \multicolumn{4}{c}{ SST $\left({ }^{\circ} \mathrm{Brix}\right)$} \\
\cline { 2 - 9 } & $\mathrm{T} 1$ & $\mathrm{~T} 2$ & $\mathrm{~T} 3$ & $\mathrm{~T} 4$ & $\mathrm{~T} 1$ & $\mathrm{~T} 2$ & $\mathrm{~T} 3$ & $\mathrm{~T} 4$ \\
\hline NB & $15,15 \mathrm{abA}$ & $15,59 \mathrm{aA}$ & $14,68 \mathrm{bA}$ & $15,21 \mathrm{abA}$ & $6,60 \mathrm{aB}$ & $6,39 \mathrm{aB}$ & $6,82 \mathrm{aB}$ & $6,66 \mathrm{aB}$ \\
NR & $14,96 \mathrm{abAB}$ & $15,38 \mathrm{aAB}$ & $14,55 \mathrm{bA}$ & $15,08 \mathrm{abAB}$ & $6,87 \mathrm{aB}$ & $6,59 \mathrm{aB}$ & $7,03 \mathrm{aB}$ & $6,98 \mathrm{aB}$ \\
Concord & $14,65 \mathrm{aB}$ & $14,81 \mathrm{aB}$ & $14,48 \mathrm{aA}$ & $14,58 \mathrm{aB}$ & $7,86 \mathrm{aA}$ & $7,70 \mathrm{aA}$ & $8,03 \mathrm{aA}$ & $7,79 \mathrm{aA}$ \\
\hline CV $(\%)$ & \multicolumn{5}{c}{9,35} & \multicolumn{5}{c}{11,48} \\
\hline
\end{tabular}

Médias seguidas pela mesma letra, minúscula na linha e maiúscula na coluna, não diferem significativamente, pelo teste de Duncan, a $5 \%$ de probabilidade.

TABELA 3 - Número de brotações mistas por planta procedentes da poda verde para a obtenção da segunda safra de uva nas cvs. Niagara Branca (NB), Niagara Rosada (NR) e Concord. Eldorado do Sul-RS, 2007/2008.

\begin{tabular}{ccccc}
\hline \multirow{2}{*}{ Cultivar } & \multicolumn{4}{c}{ Número de brotações mistas } \\
\cline { 2 - 5 } & T1 & T2 & T3 & T4 \\
\hline NB & $4 \mathrm{bA}$ & $3 \mathrm{bA}$ & $12 \mathrm{aA}$ & $4 \mathrm{bA}$ \\
NR & $3 \mathrm{bA}$ & $3 \mathrm{bA}$ & $9 \mathrm{aB}$ & $3 \mathrm{bA}$ \\
Concord & $2 \mathrm{bA}$ & $3 \mathrm{bA}$ & $6 \mathrm{aC}$ & $3 \mathrm{bA}$ \\
\hline CV $(\%)$ & \multicolumn{4}{c}{12,46}
\end{tabular}

Médias seguidas por mesma letra, minúscula na linha e maiúscula na coluna, não diferem significativamente, pelo teste de Duncan, a $5 \%$ de probabilidade. 
TABELA 4 - Produção média por planta e massa média do cacho na segunda colheita das cvs. Niagara Branca (NB), Niagara Rosada (NR) e Concord. Eldorado do Sul-RS, 2007/2008.

\begin{tabular}{ccccccccc}
\hline \multirow{2}{*}{ Cultivar } & \multicolumn{3}{c}{ Produção média $\left(\mathrm{kg} \mathrm{planta}^{-1}\right)$} & \multicolumn{4}{c}{ Massa média $\left(\right.$ g cacho $\left.^{-1}\right)$} \\
\cline { 2 - 9 } & T1 & T2 & T3 & T4 & T1 & T2 & T3 & T4 \\
\hline NB & $0,31 \mathrm{bA}$ & $0,28 \mathrm{bA}$ & $1,26 \mathrm{aA}$ & $0,34 \mathrm{bA}$ & $84,25 \mathrm{aA}$ & $83,33 \mathrm{aA}$ & $90,92 \mathrm{aA}$ & $85,08 \mathrm{aA}$ \\
NR & $0,21 \mathrm{bA}$ & $0,25 \mathrm{bA}$ & $0,84 \mathrm{aB}$ & $0,24 \mathrm{bA}$ & $72,17 \mathrm{aB}$ & $73,53 \mathrm{aB}$ & $77,76 \mathrm{aB}$ & $74,50 \mathrm{aB}$ \\
Concord & $0,16 \mathrm{bA}$ & $0,18 \mathrm{bA}$ & $0,48 \mathrm{aC}$ & $0,19 \mathrm{bA}$ & $47,83 \mathrm{aC}$ & $48,63 \mathrm{aC}$ & $52,58 \mathrm{aC}$ & $49,67 \mathrm{aC}$ \\
\hline CV $(\%)$ & \multicolumn{3}{c}{15,95} & & & & \multicolumn{2}{c}{12,42}
\end{tabular}

Médias seguidas pela mesma letra, minúscula na linha e maiúscula na coluna, não diferem significativamente, pelo teste de Duncan, a $5 \%$ de probabilidade.

TABELA 5 - Sólidos solúveis totais (SST) e acidez total titulável (ATT) dos frutos na segunda colheita das cvs. Niagara Branca (NB), Niagara Rosada (NR) e Concord. Eldorado do Sul-RS, 2007/2008.

\begin{tabular}{|c|c|c|c|c|c|c|c|c|}
\hline \multirow{2}{*}{ Cultivar } & \multicolumn{4}{|c|}{ SST ( ${ }^{\circ}$ Brix) } & \multicolumn{4}{|c|}{$\operatorname{ATT}\left(\mathrm{cmol} \mathrm{L}^{-1}\right)$} \\
\hline & $\mathrm{T} 1$ & $\mathrm{~T} 2$ & Т3 & $\mathrm{T} 4$ & $\mathrm{~T} 1$ & $\mathrm{~T} 2$ & Т3 & $\mathrm{T} 4$ \\
\hline NB & 14,33abA & $14,71 \mathrm{aA}$ & $14,17 \mathrm{bA}$ & $14,22 \mathrm{abA}$ & $7,57 \mathrm{aB}$ & 7,62aB & $7,50 \mathrm{aB}$ & $7,55 \mathrm{aB}$ \\
\hline NR & $14,27 \mathrm{abA}$ & $14,55 \mathrm{aA}$ & $13,89 \mathrm{bA}$ & 14,10abA & $7,85 \mathrm{aB}$ & 7,82aB & 7,63aB & $7,70 \mathrm{aB}$ \\
\hline Concord & $13,63 a \mathrm{~B}$ & $13,91 \mathrm{aB}$ & $13,72 \mathrm{aA}$ & $13,73 a \mathrm{~A}$ & $8,53 a A$ & $8,52 \mathrm{aA}$ & $8,32 \mathrm{aA}$ & $8,63 a A$ \\
\hline CV(\%) & \multicolumn{4}{|c|}{7,85} & \multicolumn{4}{|c|}{10,36} \\
\hline
\end{tabular}

Médias seguidas pela mesma letra, minúscula na linha e maiúscula na coluna, náo diferem significativamente, pelo teste de Duncan, a $5 \%$ de probabilidade.

TABELA 6 - Área foliar por fruto, em $\mathrm{m}^{2} \mathrm{~kg}^{-1}$, na segunda produção de uva para as cvs. Niagara Branca (NB), Niagara Rosada (NR) e Concord. Eldorado do Sul-RS, 2007/2008.

\begin{tabular}{ccccc}
\hline \multirow{2}{*}{ Cultivar } & \multicolumn{4}{c}{ Área foliar/fruto $\left(\mathrm{m}^{2} \mathrm{~kg}^{-1}\right)$} \\
\cline { 2 - 5 } & $\mathrm{T} 1$ & $\mathrm{~T} 2$ & $\mathrm{~T} 3$ & $\mathrm{~T} 4$ \\
\hline $\mathrm{NB}$ & $8,61 \mathrm{aB}$ & $9,03 \mathrm{aB}$ & $5,14 \mathrm{bB}$ & $8,48 \mathrm{aB}$ \\
NR & $9,24 \mathrm{aAB}$ & $8,94 \mathrm{aB}$ & $5,95 \mathrm{bB}$ & $9,18 \mathrm{aAB}$ \\
Concord & $10,49 \mathrm{aA}$ & $11,37 \mathrm{aA}$ & $8,43 \mathrm{bA}$ & $10,35 \mathrm{aA}$ \\
\hline CV $(\%)$ & & 14,72
\end{tabular}

Médias seguidas pela mesma letra, minúscula na linha e maiúscula na coluna, não diferem significativamente, pelo teste de Duncan, a $5 \%$ de probabilidade.

TABELA 7 - Características químicas da primeira e segunda safras das cultivares Niagara Branca (NB), Niagara Rosada (NR) e Concord. Eldorado do Sul-RS, 2007/2008.

\begin{tabular}{ccccccc}
\hline \multirow{2}{*}{ Cultivar } & \multicolumn{2}{c}{ SST $\left({ }^{\circ}\right.$ Brix $)$} & \multicolumn{2}{c}{ ATT $\left(\mathrm{cmol} \mathrm{L}^{-1}\right)$} & \multicolumn{2}{c}{ SST/ATT } \\
\cline { 2 - 7 } & $1^{\mathrm{a}}$ safra & $2^{\mathrm{a}}$ safra & $1^{\mathrm{a}}$ safra & $2^{\mathrm{a}}$ safra & $1^{\mathrm{a}}$ safra & $2^{\mathrm{a}}$ safra \\
\hline NB & $15,17 \mathrm{aA}$ & $14,35 \mathrm{bA}$ & $6,62 \mathrm{bB}$ & $7,56 \mathrm{aB}$ & $18,33 \mathrm{aA}$ & $15,19 \mathrm{bA}$ \\
NR & $15,02 \mathrm{aAB}$ & $14,27 \mathrm{bA}$ & $6,87 \mathrm{bB}$ & $7,75 \mathrm{aB}$ & $17,49 \mathrm{aB}$ & $14,73 \mathrm{bA}$ \\
Concord & $14,63 \mathrm{aB}$ & $13,75 \mathrm{bB}$ & $7,84 \mathrm{bA}$ & $8,50 \mathrm{aA}$ & $14,99 \mathrm{aC}$ & $12,94 \mathrm{bB}$ \\
\hline CV $(\%)$ & \multicolumn{2}{c}{9,21} & \multicolumn{2}{c}{11,58} & \multicolumn{2}{c}{8,56}
\end{tabular}

Médias seguidas pela mesma letra, minúscula na linha e maiúscula na coluna, não diferem significativamente, pelo teste de Duncan, a $5 \%$ de probabilidade. 


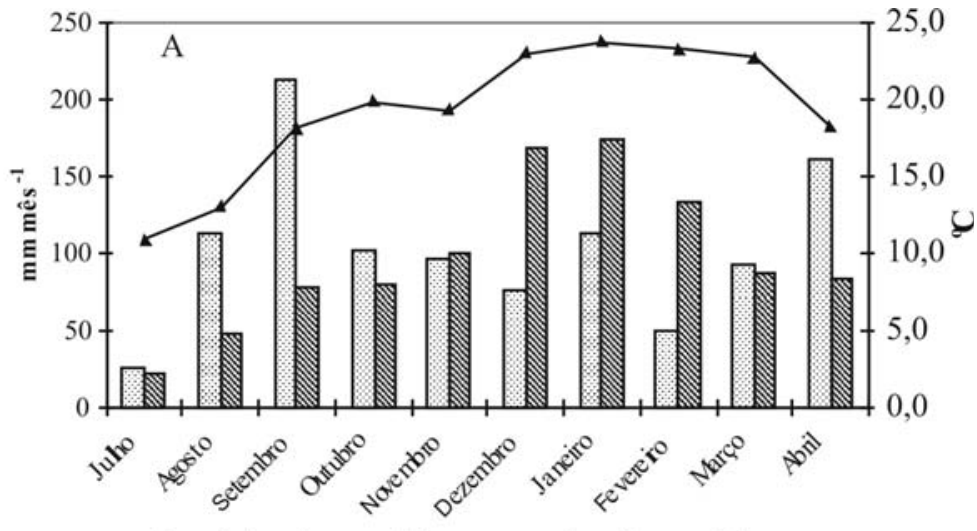

$\square$ Precipitação Evapotranspiração —Temperatura

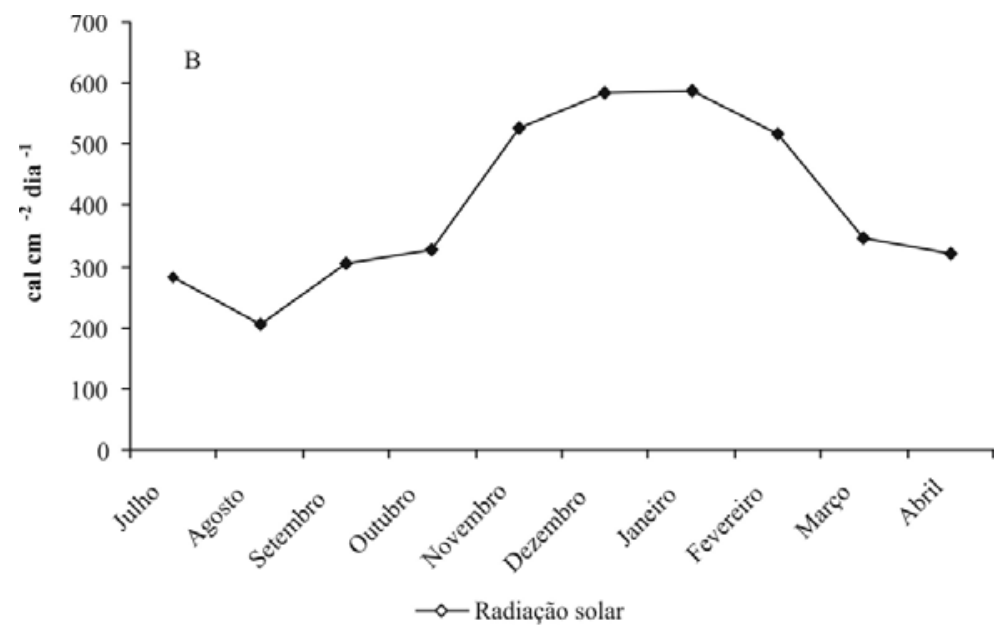

FIGURA 1 - Temperatura média do ar $\left({ }^{\circ} \mathrm{C}\right)$, precipitação pluvial ( $\mathrm{mm}$ mês $\left.{ }^{-1}\right)$ e evapotranspiração de referência (mm mês $\mathrm{s}^{-1}$ ) (A) e radiação solar global (cal cm² dia $^{-1}$ ) (B), de julho de 2007 a abril de 2008, observadas em estação meteorológica automática. Eldorado do Sul-RS, 2007/2008.

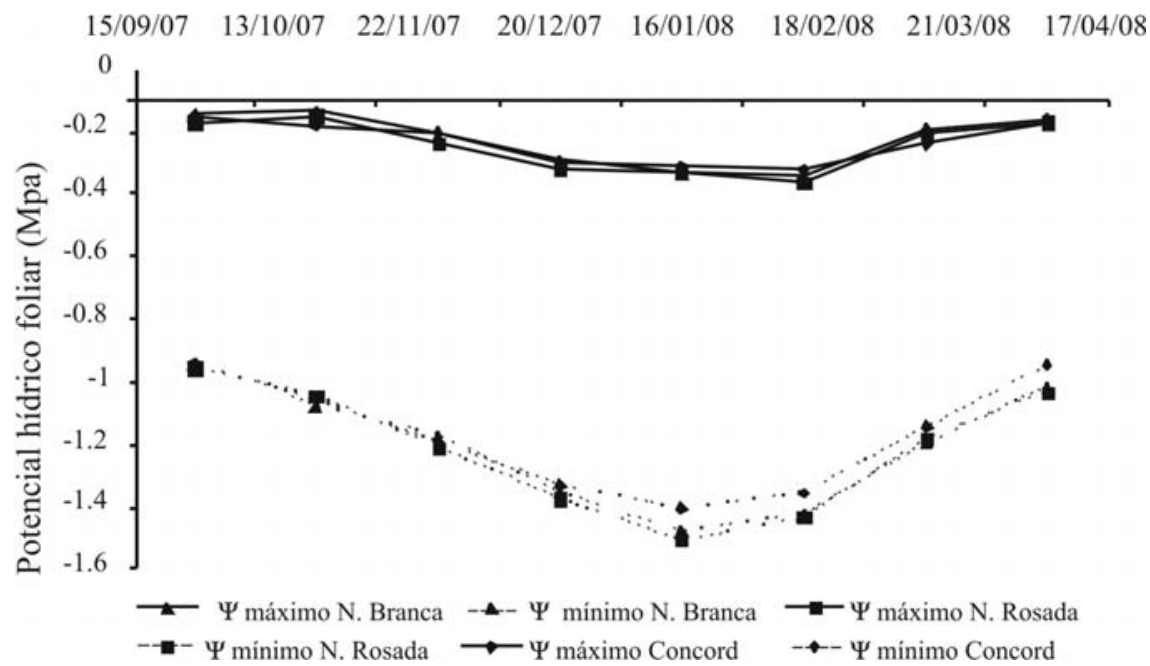

FIGURA 2 - Potencial da água máximo e mínimo na folha ao longo do ciclo vegetativo das cvs. Niagara Branca, Niagara Rosada e Concord. Eldorado do Sul-RS, 2007/2008. 


\section{CONCLUSÕES}

1-A execução de uma poda seca associada a uma poda verde permite a obtenção de duas safras de uva por ciclo vegetativo em 'Niagara Branca', Niagara Rosada e 'Concord', sendo a maior produção na segunda safra, obtida quando a poda seca é realizada em agosto associada à poda verde em novembro.

2-O potencial produtivo de uma segunda safra oriunda da poda verde depende da cultivar empregada.

3-A prática da poda verde confere menor produção às plantas se comparada à produção procedente da poda seca.

4-O número de brotações provenientes da poda verde governa a quantidade e a qualidade de uva produzida, em ambas as safras.

\section{REFERÊNCIAS}

ANZANELLO, R.; GONZATTO, M.P.; SOUZA, P.V.D.de. Produção de videiras 'Niagara Branca' e 'Concord' submetidas a duas safras por ciclo vegetativo na Depressão Central do Rio Grande do Sul. Scientia Agraria, Curitiba, v. 9, n. 3, p. 311-316, 2008.

BERGAMASCHI, H.; GUADAGNIN, M.R.; CARDOSO, L.S.; SILVA, M.I.G.da. Clima da Estação Experimental da UFRGS (e região de abrangência). Porto Alegre: UFRGS, 2003. 78p.

CAMARGO, U.A. Uvas do Brasil. Brasília: EMBRAPA-SPI, 1994. 90p.

CHADHA, K.L.; SHIKHAMANY, S.D. The grape: improvement, production and postharvest management. New Delhi: Malhotra Publishing House, 1999. 579p.

CHAMPAGNOL, F. Éléments de physiologie de la vigne et de viticulture generale. Montpellier: Déhan, 1984. 351p.

FAO. Produção e área cultivada de uvas no mundo. 2008. Disponível em: <http://www.fao.org>. Acesso em: 21 set. 2008.

FOCHESATO, M.L.; SOUZA, P.V.D.de; AGOSTINI, S. Obtenção de duas safras por ciclo vegetativo pelo manejo da poda. Revista Agropecuária Catarinense, Florianópolis, v. 20, n. 1, p. 53-57, 2007.

GIL, G.F. Fruticultura: La producción de frutas de clima templado, subtropical y uva de vino. $3^{\text {rd }}$ ed. Santiago: Universidad Catolica de Chile, 2000. 583p. GIOVANINNI, E. Produção de uvas para vinhos, suco e mesa. Porto Alegre: Renascença, 1999. 364p.

GUERRA, C.C.; DAUD, C.E.; RIZZON, L.A. Evolução dos ácidos tartárico e málico durante a maturação de uvas tintas. Pesquisa Agropecuária Brasileira, Brasília, v. 27, n. 3, p. 479-491, 1992.

IBGE. Produção vegetal. agricultura: uva, 2007. Disponível em: <http://www.ibge.gov.br>. Acesso em: 22 ago. 2007.

MELLO, O. de; LEMOS, R.C.; ABRÃO, P.U.R.; AZOLIN, M.A.D.; SANTOS, M.C.L. dos; CARVALHO, A.P. Levantamento em série dos solos do Centro Agronônico. Revista da Faculdade de Agronomia e Veterinária da Universidade Federal do Rio Grande do Sul, Porto Alegre, v. 8, n. 1/40, p. 7-155, 1966.

OJEDA, H.; DELOIRE, A.; WANG, Z.; CARBONNEAU, A. Determinación y control del estado hídrico de la vid. Efectos morfológicos y fisiológicos de la restriction hídrica en vides. Viticultura Enología Profesional, La Rioja, v. 90, p. 27-43, 2004.

POMMER, C.V.; TERRA, M.M.; PIRES, E.J.P. Cultivares, melhoramento e fisiologia. In: POMMER, C.V. Uva: tecnologia de produção, pós-colheita, mercado. Porto Alegre: Cinco Continentes, 2003. p. 109-152.

SCHIEDECK, G. Ecofisiologia da videira e qualidade da uva Niágara Rosada conduzida sob estufa plástica. 1996. 111f. Dissertação (Mestrado em Fitotecnia) -Faculdade de Agronomia, Universidade Federal do Rio Grande do Sul, Porto Alegre, 1996.

SHALTOUT, A.; SALEM, A.T.; KILANY, A. Effect of pre-bloom sprays and soil drenches of paclobutrazol on growth, yield, and fruit composition of 'Roumi Red' grapes. Journal of the American Society for Horticultural Science, Alexandria, v. 113, n. 1, p. 13-17, 1988.

SCHOLLANDER, R. F. et al. Sap pressure in vascular plants. Science, London, v. 148, p. 339-346, 1965.

SOUZA, P.V.D.de; FOCHESATO, M.L. Emprego da poda verde para obtenção de duas safras por ciclo vegetativo em 'Niagara Branca'. Bragantia, v. 66, n. 4, p. 527-533, 2007.

TONIETTO, J.; FACALDE, I. Regiões vitivinícolas brasileiras: uvas para processamento. Brasília: Embrapa Informação Tecnológica, 2003. 134p. 